\title{
Cobertura y desamparo: garantías jurídicas de los españoles en el Perú (1870-1945)1/
}

\author{
Coverage and helplessness: legal guarantees \\ of the spanish in Peru (1870-1945)
}

Núria Sala $i$ Vila

Universitat Girona

Los fondos de Prefectura del Ministerio de Relaciones Exteriores del Perú son un mirador para reconstruir la amplia casuística legal en la que se verán inmersos españoles residentes en las distintas regiones del país - bienes de difuntos intestados o sin familia en el Perú, conflictos políticos, problemas legales, fueran penales o de litigio en razón de sus actividades comerciales... - o de las gestiones de las autoridades consulares en solicitud de amparo ante decisiones de prefectos o subprefectos consideradas lesivas a sus connacionales. Se analiza el entramado legal que protegía a los españoles en el Perú, para comprender tanto los mecanismos de integración en el país, como aquellos que les llevaron a mantener la nacionalidad española, aún cuando hubieran tejido amplios intereses familiares y de negocios.

Palabras ClaVE: Perú —Regiones, XIX-XX—; Emigrantes españoles; Agentes consulares.

The archives of the Prefecture of the Peruvian Ministry of Foreign Affairs provide a perspective from which to reconstruct the broad range of legal circumstances in which Spanish residents in various regions of the country find themselves immersed (assets of relatives who have died without wills or family in Peru, political conflicts, legal problems whether criminal or civil as a result of business activities-or the requested intervention of consular authorities when decisions considered detrimental to their compatriots are made by prefects and sub-prefects). The legal framework protecting Spanish nationals in Peru is analysed to understand the mechanisms of immigration in the country and the mechanisms that led them to keep their Spanish nationality, even after establishing wide-reaching family and business interests.

KEYWORDS: Peru —Regions, $19^{\text {th }}-20^{\text {th }}$ centuries—; Spanish Nationals; Consular complaints.

1 Investigación financiada por el Proyecto HUM 2005-00610, Dirección General de Investigación del Ministerio de Educación y Ciencia. 
La migración extranjera en el Perú republicano ha sido en gran parte incorporada al imaginario nacional como un referente del proceso de modernización del país iniciado al promediar el siglo XIX. Comerciantes, mineros, industriales, profesionales y técnicos procedentes de distintos países habrían renovado los intereses y actitudes de los sectores productivos del país andino, proceso en el que sería relevante el papel de la migración europea. ${ }^{2}$ Tras la Guerra del Pacífico (1879-1884) se produjeron cambios sustanciales en las economías regionales, articuladas en torno al circuito lanero del sur, la minería del centro, la agricultura de exportación y las pujantes ciudades de la costa norte o los productos tropicales que dinamizaron la Amazonía y diversas zonas aledañas serranas, e incluso en las más diversas regiones del interior, donde los comerciantes, en muchos casos extranjeros, actuaban de agentes modernizadores. ${ }^{3}$ La historiografía económica dependentista puso el énfasis en la penetración del capital internacional de la mano de agentes o casas comerciales inglesas y norteamericanas. ${ }^{4}$ Los estudios migratorios han señalado la complejidad del proceso, en el que, por ejemplo, los italianos constituían un sector dinámico de pequeños y medianos industriales, artesanos o agricultores, ${ }^{5}$ los japoneses serían incorporados como peones en las haciendas costeras o abrirían al comercio los otrora mercados tradicionales en las ciudades rurales del interior ${ }^{6} \mathrm{o}$ los chinos, inicialmente incorporados como mano de obra barata en las haciendas costeñas o en la extracción guanera, ocuparían espacios de mayor diversificación económica, como en actividades agrarias en los frentes colonizadores tropicales. ${ }^{7}$

2 Bonfiglio, Giovanni: La presencia europea en el Perú, Congreso del Perú, Lima, 2001.

3 Mörner, Magnus: Notas sobre el comercio y los comerciantes del Cusco desde fines de la colonia hasta 1930, IEP, Lima, 1979; Glave, Luis M. y Urrutia, Jaime: "Radicalismo político en elites regionales: Ayacucho 1930-1956”, Debate Agrario, 31, Lima, 2000, págs. 1-37; Santos, Fernando y Barclay, Frederica: La Frontera domesticada. Historia económica y social de Loreto, 1850-2000. PUCP, Lima, 2002.

4 Bonilla, Heraclio (comp.): Gran Bretaña y el Perú: informes de los cónsules británicos: 1826-1900. IEP-Banco Industrial del Perú, Lima, 1975; Flores Galindo, Alberto: Arequipa y el sur andino, siglos XVIII-XX, Horizonte, Lima, 1977.

5 Bonfiglio, Giovanni: Los italianos en el Perú, Saywa, Lima, 1993.

6 Marimoto, Amelia: Los japoneses y sus descendientes en el Perú, Ediciones del Congreso de la República del Perú, Lima, 1999.

7 Rodríguez Pastor, Humberto: Hijos del celeste imperio, Lima, 1989. Lausent-Herrera, Isabelle: "Frentes pioneros chinos y desarrollo regional en la selva central del Perú", en García, P. y Sala i Vila, N. (eds.): La nacionalización de la Amazonía, Universitat de Barcelona, Barcelona, 1998, págs. 127-154. 
En el caso que nos ocupa, la influencia y desencuentros entre España y el Perú republicano ha sido analizada desde la historia diplomática, ${ }^{8}$ aunque sólo en fechas recientes se ha abordado el estudio de la migración española, ${ }^{9}$ sus características ${ }^{10}$ y sus actividades profesionales o económicas, ${ }^{11}$ apuntándose su presencia en las diversas regiones del país andino. Nuestra aportación irá en el sentido de centrarnos en quienes se asentaron fuera de Lima, en las más diversas regiones, y analizar el entramado legal que protegía a los españoles en el Perú, para comprender tanto los mecanismos de integración en ese país, como aquellos que les llevaron a mantener la nacionalidad española, aún cuando hubieran tejido amplios intereses familiares y de negocios. La documentación consultada es fundamentalmente el fondo de Prefecturas del Ministerio de Relaciones Exteriores peruano, complementada con los fondos relativos al Perú conservados en los Archivos del Ministerio de Asuntos Exteriores y General de la Administración de España.

En las últimas décadas del siglo XIX se fue tejiendo una amplia red de representaciones consulares españolas distribuidas por casi todo el Perú. Su número fue creciendo a la par que aumentaba el número de migrantes españoles que se afincaban a lo largo del país, debido a la atracción que presuponía el paulatino auge de nuevos polos de desarrollo. Aparte del Consulado de Lima y el Callao, se crearon otros en las siguientes ciudades: en el norte en Trujillo, Chiclayo, Lambayeque, Pacasmayo, Paita, Sullana, Cajamarca e Iquitos; en el norte Chico, en Huacho, Pacasmayo y Chimbote y en la costa central en Pisco; en la Sierra Central en Cerro de Pasco y Huancavelica; en el sur andino en Arequipa, Mollendo, Islay, Tacna y Arica hasta la ocupación chilena, y Cusco. ${ }^{12}$

8 Novak, Fabián: Las relaciones entre el Perú y España (1821-2000), PUCP, Lima, 2001. Martínez Riaza, Ascensión: "La lealtad cuestionada. Adscripción política y conflicto de autoridad en la representación española en el Perú, 1933-1939”, Hispania, vol. 66, n. 233, Madrid, 2006, págs. 671694 y En el Perú y al servicio de España. La trayectoria del cónsul Antonio Pinilla Rambaud, 19181939, IRA, Lima, 2008; Martínez Riaza, Ascensión y Moreno Cebrián, Alfredo: "Al servicio de la República: la acción exterior de España en el Perú, 1931-1936”, Revista de Indias, vol. 67, n. ${ }^{\circ} 241$, Madrid, 2007, págs. 713-762.

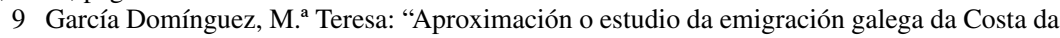

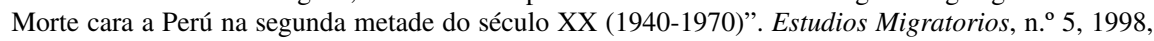
págs. 177-197.

10 Martínez Riaza, Ascensión: A pesar del gobierno: españoles en el Perú, 1879-1939. CSIC, Madrid, 2006.

11 Martínez Riaza, Ascensión: "La compañía trasatlántica en el Perú: intereses diplomáticos y comerciales en la génesis y desarrollo de una empresa arriesgada (1899-1935)", Anuario de Estudios Americanos, vol. 60, n. ${ }^{\circ}$, Sevilla, enero-junio 2003, págs. 157-182.

12 Archivo General de la Administración (en adelante AGA), 71/11913. 
La mayoría de vicecónsules y cónsules honorarios fueron escogidos entre quienes habían logrado una cierta posición social y económica en los distintos departamentos como hacendados, industriales, mineros o comerciantes, quizás porque se presuponía que por ello gozaban de prestigio y reconocimiento ante las autoridades peruanas y dentro de la comunidad de migrantes españoles. Y serían ellos los encargados de defender los intereses de los españoles que se vieron implicados en diversos actos judiciales o que consideraban lesionados sus intereses ante la representación diplomática española o ante las autoridades regionales y el Ministerio de Relaciones Exteriores peruanos.

\section{Garantías administrativas y penales a españoles}

No es fácil establecer la casuística de las competencias consulares en defensa de los intereses de los ciudadanos españoles ante las autoridades competentes peruanas. De entrada la documentación no siempre es precisa en la descripción del origen del litigio,$^{13}$ en otros casos da la sensación de que tuvieron cabida desde los casos más peregrinos, como muestra el reclamo de una maleta por el súbdito español Antonio Carrera desde Chiclayo, ${ }^{14}$ la petición de provisión de pasajes a familiares o allegados para cruzar el Atlántico $^{15}$ o que Marcos Moreno pidiera una intercesión que evitara la demolición de parte de su casa en Trujillo, afectada por el trazado de una nueva calle. ${ }^{16}$

13 No siempre ha sido posible documentar con detalle las diversas alegaciones presentadas ante el gobierno peruano solicitando garantías o en defensa de intereses de españoles residentes en el Perú y como ejemplo aportamos dos casos del Archivo Central del Ministerio de Relaciones Exteriores del Perú (en adelante ACMRREEP), 2 - O- E, 1921, queja sin especificar de Cayetano Rosich; Prefectura de Lima al oficial mayor, 15 de marzo de 1921; 2 - O - E, 1927, prefecto La Libertad al oficial mayor, Trujillo, 10 de noviembre de 1928, informando que había ordenado al subprefecto de la Provincia de Pacasmayo que practicase una investigación minuciosa sobre las dificultades que ha tenido el súbdito de nacionalidad española José Maya Motola y adopte a su vez las medidas convenientes para que se le rodee de las garantías a que tiene derecho.

14 Ibidem, 2 - O - E, 1899, José M. Rodríguez y R., prefecto de Lambayeque al oficial mayor, Chiclayo, 10 de octubre de 1899.

15 Ibidem, 2 - O - E, 1914, prefecto de La Libertad al oficial mayor, Trujillo, 20 de febrero de 1914; 1922, Enrique Zegarra, Dirección del Ramo, Sección de Inmigración, Colonización y Propaganda, Ministerio de Fomento al oficial mayor, Lima 15 de julio de 1922.

16 Ibidem, 6-13, Solicitud de Marcos Moreno, s.f., transferida en 2 de diciembre de 1915 al Ministerio de Fomento; 2 - O - E, 1916, G. Velarde, Prefectura departamento La Libertad al oficial mayor, Trujillo, 16 de febrero de 1916 y de Elías Lizarzaburu, Alcaldía del Honorable Concejo Provincial de Trujillo, al prefecto, 11 de febrero de 1916. 
A otra escala, la intervención consular defendió que se hiciera justicia en casos luctuosos, que afectaran o implicaran a españoles. El primer supuesto se dio en el del homicidio de la familia compuesta por Simón Galdeano, su hermana María y el esposo de esta, Fernando Aguilar, así como los hijos de los dos últimos, Antonio y Cecilio, junto la esposa embarazada del segundo, Angustias, y sus hijos Francisco, Cecilio y Antonio, además de Juan B. Linares, empleado de confianza y peruano, y uno de los autores, Pedro Chumbe, ocurrido los días 9 y 11 de noviembre de 1917. Los autores materiales del magnicidio fueron Tobías Meléndez, Guillermo Navarro y J. Zacarías Ramírez, instigados por Fabián Torres, suegro de Meléndez y Ramírez, quienes además saquearon la finca, robaron dinero y varios objetos y tiraron los libros de contabilidad al río, actuando supuestamente porque les pagaban a bajo precio sus productos. El 24 de noviembre de 1917, el vicecónsul en Iquitos, José Altimira, pedía el castigo ejemplar de los criminales, "pues de lo contrario será imposible que las familias y particulares españoles residan en este país puesto que por fatalidad siempre suceden casos que quedan impunes". ${ }^{17} \mathrm{El}$ alegato tenía algo de premonitorio, ya que en 1922 la Legación española reiteraba la petición, a instancias del cónsul en Iquitos, ante el Ministerio de Relaciones Exteriores, adjuntando la memoria anual del presidente de la Corte Superior de Loreto, Wenceslao Pinillos Rossell, en la que se podía leer que la causa se había pospuesto debido a la falta de recursos para costear el desplazamiento y comparecencia de testigos claves. ${ }^{18}$

Varios españoles se verían acusados o envueltos en diversos delitos penales, que se pueden tipificar desde pequeños robos, conductas vistas como antisociales u homicidios, En todos los casos los agentes consulares o la Legación española se interesaron por su causa ante los tribunales de justicia, o fueron informados directamente por las autoridades peruanas para que obraran en consecuencia. El primer supuesto tuvo como protagonista a Joaquín Masías, acusado de hurto de metal en 1914 y de dedicarse

17 Simón Galeano había llegado a Iquitos en 1899, tras lograr una cierta posición económica que le había permitido adquirir una casa, en 1914 había llamando a su hermana y familia, para que se instalaren como colonos en el fundo Colón en el Alto Itaya, con el fin de dedicarse a la agricultura y a la extracción de goma elástica. Ibidem, 6-13, conde de Galarza, Legación de España en Lima, a Francisco Tudela Varela, ministro de Relaciones Exteriores, Lima, 28 de enero de 1918, adjuntando copia del oficio de José Altamira, vicecónsul de España en Iquitos, al conde de Galarza, Iquitos, 24 de noviembre de 1917.

18 Ibidem, 6-13, Jaime Ojeda, Legación de España en Lima, a Alberto Salomón, ministro de Relaciones Exteriores, Lima, 2 de junio de 1922. 
a la venta de pequeñas especies robadas, cuyo proceso se alargó al implicar Masías a otra persona, que no pudo ser identificada, por lo que la Legación de España llegó a interesarse para que se resolviera en uno u otro sentido la causa penal. ${ }^{19}$ El segundo afectó a Pedro García Pardo, a quien las cosas no le fueron muy bien en el Perú, al menos así parece traslucirse de los informes que sobre él dieron las autoridades del Callao. Calificado de sujeto indeseable y de carecer de ocupación lícita, se vio implicado en una larga sucesión de incidentes: pelea y lesiones (10 de febrero de 1932): ebriedad y escándalo (26 de septiembre 1933); agresión, uso de armas y robo (8 de octubre de 1933); ebriedad, agresión, lesiones y escándalo (26 de setiembre de 1936); detenido y fichado por la Brigada de Extranjería por infracción a la Ley de Extranjería (7 de enero de 1937). A la vista de los antecedentes y de carecer de documento alguno de identidad, fue internado en la Colonia Penal El Frontón, aunque al afirmar ser español y natural de El Ferrol, se comunicó su situación al Ministerio de Relaciones Exteriores. ${ }^{20}$

En sendos casos de homicidio se acusó a españoles de haberlos cometido. El primero tuvo lugar en 1903, cuando en el transcurso de una reyerta entre el español Ramón F. Sánchez, el peruano Julio Caballero y el chino Juan Muggi, resultó muerto éste último, siendo puestos los otros dos a disposición judicial. Entre versiones encontradas, la Legación española defendió que Sánchez actuó en defensa propia, ${ }^{21}$ contra la opinión del subprefecto que atribuía a Sánchez y Caballero el asalto y muerte de Muggi en las alturas de Yanahuanca, cerca de Cerro de Pasco. ${ }^{22}$ En el segundo caso, sólo conocemos el informe del Ministerio de Relaciones Exteriores peruano del asesinato cometido el 15 de febrero de 1919 por un tal Alonso contra su ex socio, el súbdito belga Teofilo Martheleare, comerciante de caucho en los ríos Alto Piedras, Tahuamanu y quebrada Alto Canales afluente Tahuamanu, en el departamento de Madre de Dios. ${ }^{23}$

19 Ibidem, 2 - O - E, 1914, Prefectura del Callao al oficial mayor, Callao, 1 de abril de 1914; Oficio del oficial mayor, Lima 30 de marzo de 1914; Informe de Neptalí Chavarri, Callao. 4 de abril de 1914.

20 Ibidem, 1939, Prefectura del Callao al oficial mayor, El Callao, 14 de agosto de 1939.

21 Ibidem, 6-13, S.D.E. España, Legación de España en Lima al ministro de RREE, Lima, 3 de febrero de 1903.

22 Ibidem, Prefecturas, 2-O-E, Enrique N. Slee, Cerro de Pasco, 13 de enero de 1903.

23 Ibidem, 2 - O - E, 1919, C.V. Zapatel, prefectura del Madre de Dios al oficial mayor, Maldonado, 5. de mayo de 1919. 
En ocasiones fueron las autoridades peruanas las que recabaron la ayuda de la representación española para resolver algún conflicto en el que intervenía la jurisdicción eclesiástica, como ocurriría en el caso de Antonio Regnard Maciá, natural de Tarragona, denunciado en 1929 por el obispo de Arequipa porque había abandonado sus obligaciones como cura de Cojata (Puno), residiendo en Arequipa vestido de seglar; la Prefectura, tras proveerle del carnet de extranjería, le había retenido sus documentos, que fueron puestos a disposición de la representación consular española. ${ }^{24}$ En Paita, producto de la realidad o del rumor, se acusó en 1910 a un "individuo de nacionalidad española", no identificado en la documentación, de ser el responsable de la desaparición del escudo del Consulado de Ecuador, cuando "en estado de embriaguez recorrió las calles apartadas amenazando vengarse del Cónsul por no haberle prestado un servicio que le pidió durante el día". ${ }^{25}$

Si en los casos comentados hubo una amplia casuística en la que o bien agentes consulares o la Legación española se interesaron por asuntos conflictivos en los que se veían envueltos sus conciudadanos, o bien eran las propias autoridades peruanas las que les informaban en todo momento de los sucesos en que se veían comprometidos migrantes españoles, sería la defensa de sus intereses económicos, como veremos a continuación, la que ocuparía la mayor parte de sus desvelos.

\section{La defensa de los intereses económicos de ciudadanos españoles}

Una de las competencias, no menor, de los agentes consulares fue el velar por la defensa de los intereses de los migrantes difuntos y de sus herederos. En aquellas ciudades o zonas donde no existían representantes consulares, eran las autoridades locales y regionales quienes daban aviso al Ministerio de Relaciones Exteriores para que se informara a las autoridades españolas competentes. ${ }^{26}$ En conjunto existían una serie de procedimientos y garantías que hemos constatado que se aplicaron en múltiples

24 Ibidem, 1929, Prefectura de Arequipa al oficial mayor, 25 de junio de 1929. de 1910 .

25 Ibidem, 1910, Juan S. Seminario, prefectura de Piura, al oficial mayor, Piura, 31 de marzo

26 Nos abstenemos de aportar una prolija referencia de la documentación, para abreviar en lo posible la extensión del artículo, y sólo anotamos la referencia genérica donde se conservan: Ibidem, 6 - 13, S.D.E. España (1891-1897) y 2-O-E, (1897-1939). 
casos documentados, ya que a pesar de que en cierta documentación conservada en ese Ministerio del Perú sólo consta la noticia del fallecimiento de súbditos españoles, ${ }^{27}$ en otros casos se adjuntaba una sucinta información sobre los bienes que legaba, si había muerto o no intestado, a quien se encargaba la administración de la testamentaría en caso de no existir Consulado español en la demarcación y/o a quien se hacía depositario de los bienes habidos. ${ }^{28} \mathrm{Si}$ bien los casos consultados muestran una tendencia de respeto absoluto de los intereses de los súbditos españoles fallecidos, hubo alguna queja ante supuestas trabas que encontraba algún vicecónsul para hacerse cargo de los bienes de cierto súbdito ab-intestato. ${ }^{29}$

Las causas por las que un inmigrante consideraba que se habían vulnerado sus derechos o intereses económicos fueron de muy diversa índole: contratos suscritos entre partes que no habían sido cumplidos oportunamente o a satisfacción del interesado o debidos a la inseguridad jurídica en que se movían los inversores. Como muestra señalaremos dos casos, el que afectó al presbítero Juan de Dios Gallego Merino y el que involucró al artista Nicanor Álvarez. En el primer caso, tras regresar a España, Juan de Dios Gallego Merino pidió que el Consulado interviniera para hacer cumplir el contrato de venta de una casa suya en Tumbes, ya que al no tener representante legal en el Perú, se había puesto en remate, luego que, tras no haberse pagado lo estipulado, se pretendiera en un segundo momento devolvérsela ya en su ausencia. ${ }^{30}$ En el segundo caso, Nicanor Álvarez había recibido en la década de 1920 un encargo del Comité Pro-monumento "héroes de San Pablo de 13 de julio de 1882" de Cajamarca, con el

27 Ibidem, notificaciones relativas a: José Bilbao, Huánuco, 1891; Tomás Lombraña, Moquegua 1894; Claudio Montori, Cusco 1897; Eulogio Carrera, Pisco, 1900; Buenaventura Seluy e Hijidio Carbonells, Ica, 1906; Feliciano Ugarte y Antonio Añibano, Pisco, 1907; José Rodríguez, Balta, 1908; Manuel Bernuri y Juan Roix, Casma, 1909; Juan Marqueti, Moquegua, 1915; Juan Francisco Galera, Tumbes, 1915; Ramiro Cobian, Moquegua, 1918; Francisco Caamaño, Tumbes, 1918; Vicente Motta, Sullana, 1939.

28 Ese fue el caso de las actuaciones en las testamentarías de los súbditos españoles que se relacionan, junto al lugar y fecha de su defunción: José Ibars (Andahuaylas, 1900); Luis La Forga (Puno, 1900); Genaro Regatillo (Cerro de Pasco, 1902); Antonio Fort (Paita, 1902); Domingo Burge, (Chachapoyas, 1891); Manuel Gómez González (Cajamarca, 1905); Antonio Pedro de Robles Álvarez, (Moro, Ancahs, 1905); Arturo Armas (Ica? 1906); José María Ruiz García (Maldonado? 1913?); Ibidem, 6-13, S.D.E. España, (1900-1902) y 2 - O - E, (1902-1913).

29 Tal fue el caso denunciado por el vicecónsul en Trujillo, Antonio Bradariz, por obstrucción de las autoridades judiciales para que pudiera hacerse cargo, previo inventario, de los bienes de Juan Manuel González, fallecido en mayo de 1894. Ibidem, 6 - 13, S.D.E. España, Legación de España en Lima al ministro de RREE, 15 de enero y 12 de junio de 1895.

30 Ibidem, 6 - 13, Jaime Ojeda, Legación de España en Lima, a Alberto Salomón, ministro de Relaciones Exteriores, Barranco, 17 de abril de 1925. 
acuerdo de abonarle 2.500 soles de plata, parte a la firma del contrato y parte a la entrega de la obra. Como no estuvieron contentos con la obra entregada, al punto que creyeron conveniente perfeccionarla y pulirla por manos del constructor Héctor Castro, se negaron a cancelar lo estipulado inicialmente. Para solucionar el desacuerdo y que se le pagaran sus haberes, Álvarez recurrió a la vía consular, por la que se le contestaría que debería haber recurrido previamente al Juzgado de $1 .{ }^{\mathrm{a}}$ Instancia de Cajamarca. ${ }^{31}$

Un asunto de competencia, con denuncia por abuso de autoridad y petición de defensa de sus intereses, se evidencia en la reclamación efectuada en 1892 por los mineros Jaime Garreta y José López Salcedo contra Esteban Lagurtegui, subprefecto de la Provincia de Huarochirí. Garreta, dueño de varias minas, se sentía hostilizado tanto por disensiones en el amparo de varias minas, como por el embargo de un cajón de metales, sin orden judicial alguna, ni la intervención preceptiva de la Diputación territorial de minería. A su vez, López Salcedo debió interrumpir sus labores en el distrito de San Mateo, al aplicarse sólo a sus peones la ley de Conscripción, contra lo que establecía la ley de minas que contemplaba tal supuesto únicamente en caso de guerra. El 2 de agosto de 1891 tuvieron que interrumpir los trabajos en la mina Urresuría, en las alturas de Pomapongo (Surco), al ser atacados con armas de fuego "por asesinos conocidos por todo el pueblo y todas sus autoridades". La raíz de tal encono por parte del subprefecto provenía de la compra por parte de Garreta, con la intervención de López Salcedo, de la mina El Progreso, lo que había desbaratado los planes del subprefecto, quien la pretendía para un hermano suyo. En suma, López Salcedo pedía en compensación por daños y perjuicios la cantidad de 1.500 soles, valor de las pérdidas por la paralización de sus minas y la suspensión de la exportación de metales a Europa ${ }^{32}$ más 150 soles por cada día que continuaran afectados sus intereses. ${ }^{33}$ Algo parecido se intuye en el caso del ataque de la sucursal de los comerciantes Garagurri y Cía. en Tayabamba, efectuada en 1903 "por una indiada enca-

31 Ibidem, 2 - O - E, 1924, José Fidel Vergara al Señor Ricardo Revilla Pérez, prefecto de Cajamarca, s.f.; Copia del Contrato entre Nicanor Álvarez y el señor presbítero José Fidel Vergara Torres, presidente, y con el señor Juan del C. Correa, tesorero de un comité organizado en la ciudad de San Pablo el 13 de marzo de 1882, San Pablo, 3 de septiembre de 1923.

32 Ibidem. Legación de España, 1892, 7.2.1892. Jaime Garreta al ministro de España, Lima, 27 de enero de 1892 y José López Salcedo al ministro de España, Lima, 9 de enero de 1892.

33 AGA, 71/11912, José López Salcedo, Lima, 9 de enero de 1892 pidiendo garantías y reclamando daños y perjuicios; ibídem, Jaime Garreta, Lima, 27 de enero de 1892. 
bezada por un Señor Zegarra”, porque, al parecer, le hacían competencia a su negocio. ${ }^{34}$

Nos han llegado versiones disímiles sobre algunos litigios, según fueran de fuente de las autoridades locales o de los propios migrantes interesados, como muestran los siguientes ejemplos. En torno a 1910 se incoaría juicio militar a Tomas Rodríguez, acusado de resistencia armada, en unión de Julio Gálvez y Antonio Oliveiro, al acto de desahucio del fundo San Regis, Provincia de Bajo Amazonas. ${ }^{35}$ Tres años más tarde Rodríguez pidió protección y amparo, puesto que tras haber obtenido sentencia favorable de la Corte Superior de Justicia, no lograba retomar la posesión del fundo, a pesar de haberlo intentado en compañía del juez de 1. ${ }^{a}$ instancia y gendarmes, por la resistencia de sus ocupantes, unos señores Rocha. ${ }^{36}$ En otro caso, la colonia española de Huancayo presentó en 1914 una queja ante la falta de garantías que padecían por el trato que les deparaba el subprefecto. Éste, sin embargo, informó que el malestar obedecía al arresto de Ramón Ruiz, tras haber contestado de forma intempestiva cuando se le citó para que respondiera sobre la instalación de dos máquinas peseteras, sin la licencia preceptiva. ${ }^{37}$

Se llegó a reclamar al Estado peruano por cambios en su política fiscal que se presuponía que atentaban contra las inversiones hechas aprovechando determinadas exoneraciones, como muestra el caso de la empresa Lambarri y Cía. del Cusco, y en su representación N. García, María Lambarri Forga e Irene Lambarri Forga, quienes en 1923 aducían verse afectados por la derogación de la ley de exoneración por cinco años del impuesto fiscal a los alcoholes producidos en los valles de Paucartambo, que debía regir hasta 20 de febrero de 1925. Según la compañía, ante la situación favorable que se presentaba y que permitía sortear los altos costes de transporte por la distancia y el mal estado o inexistencia de caminos, había denunciado varios terrenos de montaña en Paucartambo - fincas Iberia, Pelayo, Ollantay y Balmaceda - e invertido 38.386.1.61 Lp para rozarlos, plantar caña de azúcar, instalación de maquinaria, aperos y cons-

34 ACMRREEP, Legación de España, 5 de mayo de 1903.

35 Ibidem, 2 - O - E, 1910, E. Castañeda, subprefectura Bajo Amazonas, al oficial mayor, Iquitos, 11 de agosto de 1910; del Juzgado Militar Permanente de la Zona de Loreto al subprefecto e intendente de Policía, Iquitos, 11 de abril de 1910.

36 Ibidem, 6 - 13, Andrés López, Legación de España en Lima, a Francisco Tudela y Varela, 10 de septiembre de 1913 .

37 Ibidem, 2 - O - E, 1914, prefecto de Junín al oficial mayor, Cerro de Pasco, 28 de noviembre de 1914; Telégrafos del Estado, Huancayo n. ${ }^{\circ}$ 66, 27 de noviembre de 1914. 
trucción de viviendas para los operarios. Sin embargo, aseguraban que justo en la etapa inicial, cuando se habían visto obligados a afrontar la mayor parte de las inversiones necesarias, se había producido el cambio legal, lo que sólo podía suponerles mermas en sus expectativas de beneficios, por lo que, en caso de que el gobierno persistiera en tal política, Lambarri y Cía. exigía que: a) se les indemnizara por el total invertido; b) se adquirieran por la recaudadora sus productos a 35 soles por quintal en Cusco o 42 soles en Sicuani, libres de impuestos locales o regionales; o c) se les concediera, en compensación, el estanco de alcoholes en Sicuani; como consideraban que ninguna de las tres posibilidades produciría beneficios, al menos se evitaría la ruina de la empresa. ${ }^{38}$

En realidad Lambarri y Cía. aportaba una información cuanto menos parcial, amagando la realidad, ya que habían adquirido derechos sobre las fincas Iberia, Pelayo, Ollantay y Balmaseda en pleno funcionamiento, incluida la maquinaria para destilar alcoholes, tras ejecutar una hipoteca suscrita a su favor por su propietario original, el cauchero gallego Bernardino Perdiz. Éste era, junto al asturiano Máximo Rodríguez González, uno de los mayores caucheros de la vecina región del Madre de Dios. ${ }^{39}$ La crisis del caucho le afectaría, como a tantos otros, sumiéndole en un cúmulo de deudas, que, para el caso que nos ocupa, ascendían con la firma Lambarri y Cía. a 307.650,05 soles, 147.487,71 de ellos por el envío de mercancías, pago de letras giradas por él mismo a favor de dicha casa comercial y otros productos entregados a cuenta en consignaciones de caucho y los $160.162,44$ soles restantes de resultas de haberle prestado mercancías y dinero para "la instalación y cultivos" de las haciendas Iberia, Pelayo y Ollanta, lo que le obligó a transferir las haciendas Iberia y Pelayo a favor de Lambarri y Cía. Con fecha de 14 de marzo de 1919 y, posteriormente, el 16 de octubre de 1920 se comprometió a seguir explotando las fincas, aportando para ello "todo su personal indio, compuesto de más de 200 personas, cuyos jornales atenderá con sus intereses del Madre de Dios", garantizando la casa Lambarri que seguiría habilitando a Perdiz con cargo a un préstamo de 2.500 soles mensuales a un interés mensual del 1\%, que debería ser cancelado al siguiente mes con los productos obtenidos,

38 Ibidem, 6 - 13, N. ${ }^{\circ}$ 43, Jaime Ojeda, Legación de España en Lima a Alberto Salomón, ministro de Relaciones Exteriores, Barranco, 3 de agosto de 1923, adjunta copia de la solicitud de Lambarri y Cía.

39 Delboy, Emilio: "Exploraciones y hechos históricos del Madre de Dios", Boletín de la Sociedad Geográfica de Lima, t. LXXIV, trim. 1. ${ }^{\circ}$ y 2. ${ }^{\circ}$, Lima, 1957, pág.10. 
sobre cuya comercialización adquirían derecho exclusivo; ${ }^{40}$ el 27 de octubre de 1920 se gravó el fundo Ollanta con 7.650 soles, al 1\% mensual, fundo que pasaría en 22 de marzo de 1922 a ser propiedad de María Julia de Lambarri de Villaseñor y de María Irene de Lambarri Forga para saldar 20.000 soles del total de la deuda con Lambarri y Cía., cuyo total ascendía por entonces ya a $330.255,75$ soles. $^{41}$

Mariano Querol Pasamón, natural de Orgaña en Lérida, solicitó los buenos oficios de la Legación española para que se le expidiera definitivamente el título de propiedad de 400 hectáreas, la finca Isona, en los valles de Paucartambo. El trámite se había complicado porque Bernardino Perdiz había objetado tal concesión alegando que él llevaba diez años explotando esas mismas tierras, bajo la denominación de Villacarmen y, a pesar de que el gobierno peruano había reconocido el mejor derecho de Querol, no lograba que se cerrara definitivamente el caso en su favor, por lo que pedía la intercesión de la Legación española. ${ }^{42}$ En este caso, el cruce de informaciones, nos lleva a presuponer que algo tuvo que ver con los entresijos de la deuda del cauchero Perdiz con la firma Lambarri y Cía., ya que M. ${ }^{a}$ Irene Lambarri Forga se uniría, en segundas nupcias, con Mariano Querol.

El caso descrito evidencia una actuación que se situaba entre la mala fe y las verdades a medias para lograr posiciones ventajosas, a lo que se añade que la familia Lambarri había controlado, hasta fechas muy recientes y durante casi un siglo, el Viceconsulado español en el Cusco. En otros casos la estrategia de algunos empresarios españoles pudo ser la de mantener y hacer valer su nacionalidad y condición de país neutral, como una opción que les permitiera capear los momentos de crisis internacionales que les pudieran afectar. Al menos ello se evidencia en el caso de la firma Barcia Hermanos, una de las grandes casas comerciales al por mayor de

40 Archivo Regional del Cusco, Protocolos Notariales, José Alosilla, Protocolo 24, 1920, n. ${ }^{\circ}$ 1164, ff. 2491 y ss.

41 Superintendencia Nacional de los Registros Públicos, Perú, (SUNARP), Cusco, partida 02031290, tomo 63, foja 202, sección especial de predios. A su vez, la firma Lambarri y Cía. hipotecó la finca Ollanta a favor de Amsinck y Cía. Inc. de Nueva York por 10.000 soles, importe de la mitad del saldo que le adeudaban, a abonar en cinco dividendos a partir del 15 de octubre de 1924. Posteriormente, la arrendarían a la Sociedad Agrícola del Tono, representada por su gerente la casa Establissements Braillard S.A. por 5 años forzosos y 5 más voluntarios para los locatarios y forzosos para los locadores, a cambio de un canon del $5 \%$ del producto de la renta de alcoholes, incluyendo lo producido en Iberia, Pelayo y Balmaseda. Ibidem, partida 02031290, tomo 63, foja 202, Sección especial de predios.

42 ACMRREEP, 6 - 13, Nota N. ${ }^{\circ}$ 22, Jaime Ojeda, Legación de España en Lima, a Alberto Salomón, ministro de Relaciones Exteriores, Barranco, 18 de abril de 1925, adjunta copia de la petición de Mariano Querol a Jaime Ojeda, ministro de España en Perú, Lima, 16 de abril de 1925. 
Iquitos, propietaria de gomales -fundos Galicia, Puerto Socorro, Préñaley dedicada a la extracción de caucho, de lejos el mayor contribuyente de origen español en Loreto. ${ }^{43}$ En plena Primera Guerra Mundial se les decomisó en Liverpool un envío de 20.404 kilos de caucho, valorados en Iquitos en 4.070 libras, fletados en el vapor Atahualpa de la Compañía Booth y a la consignación de Alberto Winkelmann con destino al puerto de Hamburgo. Los socios de la empresa, José y Generoso Barcia Bonet y Eduardo Porto, originarios de Padronos en Puenteareas, Pontevedra, alegando su nacionalidad y la neutralidad española en el conflicto bélico, pidieron una indemnización de 10.000 libras del gobierno inglés para resarcirse del importe de lo confiscado, de la paralización del capital, gastos de protestos y de la pérdida de confianza de su compañía. Este es uno de los pocos casos en que hemos constatado que no se recurrió a las autoridades consulares, sino que los Barcia intercedieron ante el diputado Rodrigo Soriano Domínguez, quién comunicó el caso al ministro de Estado, marqués de Lema, ${ }^{44}$ quién instó a que interviniera la representación consular en Londres. El caso era complejo ya que las autoridades inglesas desestimaron la vía consular, derivándolo a la judicial y, en concreto, al Tribunal de Presas, ya que éste había condenado las mercancías y las había subastado. A fines de 1915 los reclamantes estimaban posible que se aceptaran nuevas pruebas, que demostraran que el caucho pertenecía a neutrales. ${ }^{45}$

\section{Los españoles y sus bienes en el devenir de la política peruana}

Las convulsiones políticas del Perú afectaron, como no podía ser de otra forma, a españoles asentados en el país y a sus bienes. Si algunas reclamaciones son testimoniales y parecen indicar que sólo afectaron a unos

43 Fuentes, Hildebrando: Loreto. Apuntes geográficos, históricos, estadísticos, políticos y sociales, Imprenta de la Revista, Lima, 1908, t. II; Guía Lascano, 1924; Santos y Barclay: La frontera domesticada, pág. 121, cuadro 4.4, según los cuales en 1907 sería el séptimo exportador de goma de Loreto, controlando el 5,2\% del total regional, por detrás de Arana Hnos, Marius, Levy \& Schuler, Kahn\&Cia, Iquitos Trading Co., Kahn\&Polack.

44 Archivo del Ministerio de Asuntos Exteriores (en adelante AMAE), Política, Política exterior, H 2508, Exp. 23, 1, Reclamación Barcia Hermanos a Inglaterra, 1915. Los señores Barcia de Iquitos a don Rodrigo Soriano Domínguez, diputado a Cortes, Iquitos, 7 de septiembre de 1915; Nota del diputado Rodrigo Soriano al marqués de Lema, ministro de Estado, Madrid, 6 de noviembre de 1915; al ministro de España en Londres de José Barcia Bonete, Generoso Barcia Bonete y Eduardo Porto, Iquitos, 10 de mayo de 1915.

45 Ibidem. Copia de la carta del cónsul Alfonso Merry del Val a Barcia Hnos., Londres, 7 de junio de 1915, Informe del cónsul en Londres, José Congosto, 11 de diciembre de 1915 
pocos, en determinadas coyunturas el número de perjudicados fue mayor, por lo que, tras mencionar una serie de casos aislados y ocurridos en distintos momentos, dedicaremos apartados específicos a las reclamaciones de reparaciones como consecuencia de la Guerra del Pacífico (1879-1884), la Guerra Civil (1894-1895) y la revolución federal dirigida por el capitán Guillermo Cervantes en Iquitos (1921).

La intervención de los españoles en asuntos de política interna fue bien o mal vista, según cual fuera la situación en la que se implicaron. La defensa de la causa peruana en Tacna, costó la expulsión por parte de las autoridades chilenas de Basilio Iriarte y Bartolomé Pons, un acto que les valdría el apoyo del gobierno peruano, que asumió el coste de su repatriación a territorio peruano. ${ }^{46}$ Peor le fueron las cosas a Feliciano del Álamo, que sería detenido y juzgado en 1909 por haberse inmiscuido en las elecciones de mayo de ese año efectuadas en el distrito de Ollantaytambo en el Cusco; un hecho que mereció la protesta del vicecónsul Isidro Lambarri al considerar que había evidencia de abuso de autoridad por parte del jefe provincial de Urubamba y maltratos obrados por Guillermo Rozas, quién había actuado armado y a las órdenes del anterior. ${ }^{47}$

En algún caso, como el que comentamos a continuación, se trata de daños colaterales debidos a una pugna de la que supuestamente se era ajeno. Pedro Castillón y Penella, radicado en Mollendo, vio como, en 1893, su casa era saqueada en el transcurso del asalto e incendió de la Logia masónica Paz y Trabajo n. ${ }^{\circ} 21$, aledaña a sus aposentos, donde se celebraban los funerales masónicos en memoria del que fue Emilio Cazorla. ${ }^{48}$ En 1894 se le resarció con 700 soles por parte del Estado peruano en concepto de los bienes que había perdido. ${ }^{49}$ En otros casos parece traslucirse la quiebra de rancias tradiciones, cuestionadas por la llegada de nuevas gentes y formas económicas, una hipótesis que podría ayudar a comprender el ataque en sus respectivos domicilios a los súbditos español e italiano Ignacio Fontenla y Leopoldo Arte, comerciantes radicados en Sihuas, el 28 de enero de 1893, dirigido por el gobernador del pueblo Marcelino Valverde y por Amadeo Rivera al frente

46 ACMRREEP, 2 - O - E, 1922, prefecto de Tacna al oficial mayor, Locumba, 10 de febrero de 1922; 2-O-E, 1925, del subprefecto de Tacna al prefecto, Locumba, 8 de abril de 1925.

47 Ibidem, 1909, Pablo Dalmoz, prefecto del Cuzco, al oficial mayor, Cuzco, 4 y 8 de junio de 1909. En comunicación desde Urubamba el 27 de mayo de 1909, las autoridades locales informaban que se le había detenido durante un lapso de 10 horas por haber faltado al comandante Rossello.

48 Ibidem. Legación de España, 24 de julio de 1893, remitiendo solicitud del súbdito español, domiciliado en Mollendo, don Pedro Castillón y Penella.

49 Ibidem, 5 de agosto de 1894, ofrecidos por el MRREE y aceptado por la Legación española. 
de un número considerable de gente armada, al grito de "mueran los gringos", por lo que se pidió la protección por vía consular del subprefecto de Pomabamba..$^{50}$ En otros casos la información es sumamente escueta, mostrando sólo un conflicto evidente con las autoridades regionales, como aparece en las demandas de garantías que llegarían ante el Ministerio de Relaciones Exteriores por parte de Eugenio y Antonio Carrera, desde Chiclayo, quienes en 1900 consideraban que "fueron victimas de un atropello por parte del entonces subprefecto, Don Manuel Lastanau"; $;{ }^{51}$ y en torno a la detención supuestamente arbitraria del Dr. Mendieta en Tarapoto, seguida de la protesta de los españoles residentes en dicha ciudad denunciando los procedimientos empleados contra ellos por el subprefecto Mayor Calvo, e insistiendo en que Mendieta "jamás intervino en política". ${ }^{52}$

En la década de 1920 las reivindicaciones indígenas fueron una constante en varias regiones del Perú. No fue extraño que determinados intereses de ciudadanos españoles se vieran afectados. En algunos casos es difícil, por lo escueto de los datos aportados en la documentación oficial, saber cual era la causa del conflicto, pero es posible ver tras la detención de Manuel Fernández en Abancay y el saqueo de sus propiedades, valoradas en 20.000 Lp, "merced a intrigas y calumnias de un señor Diputado llamado Gutiérrez, que lo ha acusado de detentar armas" un altercado de raíz política, más en una coyuntura dominada por importantes conflictos agrarios..$^{53}$

Salustiano Olivares, dueño de las haciendas Yanarico, Ayagache, Cotan, Alpayoco y del lavadero de lanas en Calamillas en Lampa (Puno), quien en 1921 pidió amparo inicialmente contra "los desmanes y atropellos de los indios" y, en una segunda ocasión, convencido de que se estaba preparando "un levantamiento de la indiada para el día dos de noviembre". Se sentía indefenso, ya que no había recibido las garantías esperadas por parte de las autoridades y, por ello, solicitaba la remisión de fuerzas del orden para proteger sus propiedades, de las que ya habían huido por temor sus empleados, a cuyo pedido la Legación española intervino para recomendar verbalmente la defensa de sus intereses ante el gobierno peruano. ${ }^{54}$

50 Ibidem, Lima, 28 de junio de 1893.

51 Ibidem, 2 - O - E, 1900, I, Lino Velarde, prefectura de Lambayeque al oficial mayor, Chiclayo, 9 de abril de 1900.

52 Ibidem, 6 - 13, Jaime Ojeda, legación de España en Lima, a Alberto Salomón. ministro de Relaciones Exteriores, Lima, 12 de enero de 1924.

53 Ibidem. Nota verbal de la Legación de España en Lima, Lima, 24 de marzo de 1922.

54 Ibidem. Legación de España, Memorando de la Legación de España en Lima al Ministerio de Relaciones Exteriores, Lima, 31 de octubre de 1921. 
Salustiano Olivares Ballivián, ${ }^{55}$ era considerado por la representación consular española como perteneciente a "la gente pudiente y que ocupa cierta posición". ${ }^{56}$ Con vínculos familiares en Arequipa y La Paz desde el periodo colonial, ${ }^{57}$ cuyos antepasados directos emigraron tras la independencia, pareciera que no por ello dejaron de administrar desde la distancia sus propiedades, como se evidencia de una reclamación anterior a la que nos referiremos, al tratar las consecuencias de la Guerra del Pacífico, para asumir personalmente su dirección coincidiendo con el boom lanero.

En 1921 Puno se hallaba inmerso en un amplio conflicto cuyas raíces cabe situar en la caída de los precios de las lanas y en la subsecuente crisis agraria, aquejada además por la disímil estructura de la propiedad y las duras condiciones laborales y serviles que padecían las comunidades campesinas. Coincidiendo con la política indigenista de la primera etapa del Oncenio de Augusto B. Leguía, se produjo una amplia movilización social, articulada en torno a las actuaciones de la Comisión Especial de Investigación de la Cuestiones Indígenas del Sur de la República, al Comité Pro-Derecho Indígena Tawantinsuyo, en cuyo transcurso se produjeron varios asaltos a haciendas y represiones luctuosas contra los indígenas puneños. ${ }^{58}$ Fue en ese contexto cuando Salustiano Olivares pidió apoyo a

55 Nieto del brigadier Julián de Olivares y Manzanedo, cercano al general Espartero, e hijo de Salustiano de Olivares y Surlin Manzanedo y Careaga (+Madrid 1875) y de Victoria de Ballivián Guerra (La Paz, 1838-1913).

56 Martínez de Velasco, Ángel: "Relaciones hispano-peruanas durante la dictadura de Primo de Rivera: El centenario de Ayacucho", Quinto Centenario, 2, Madrid, 1981, pág. 182.

57 Estaba casado con la arequipeña Elvira Marcó del Pont y era padre de una numerosa prole. Su hermano Julián, I conde de Artaza, sería diputado conservador por Alcántara (Cáceres, 1914-1915) y gobernador civil de Guipuzcoa (1917), su hijo José Manuel de Olivares y Bruguera sería además II marqués de Murrieta, al heredar títulos y posesiones de su tío Luciano Francisco Ramón de Murrieta García Ortiz y Lemoine (Arequipa 1822, Logroño 1911); tras la independencia del Perú permanecería un tiempo junto a su tío el general Rivero, si bien posteriormente emigró a Londres, donde su familia se había radicado, junto a su tío y banquero Cristóbal Pascual de Murrieta y Mello, y posteriormente ingresaría en la carrera militar, llegando al grado de coronel de caballería, y vinculado al general Espartero, de quién fue ayudante de campo, le seguiría al exilio londinense entre 1843-1848, de cuya intercesión ante Amadeo de Saboya lograría su título nobiliario y se afincaría como éste en La Rioja, donde sería uno de los renovadores de la industria vitivinícola a mediados del s. XIX. Las referencia sobre su familia directa de la comunicación personal de José Rey de Castro y sobre su hermano en: Ruiz Rivas, Luis Fernando: Análisis histórico de las instituciones y realizaciones socioeducativas del ayuntamiento logroñés desde la ley Moyano hasta la ley Villar Palasí (1859-1970), tesis doctoral, Universidad de La Rioja, Logroño, 2003, págs. 109-113; véase su papel en la política en: Archivo Histórico de Diputados, 1810-1977, www.congreso.es.

58 Kapsoli, W.: Ayllus del sol: anarquismo y utopía andina, Tarea, Lima, 1984; Flores Galindo, Alberto: Buscando un Inca: identidad y utopía en los Andes, Editorial Horizonte, Lima, 1988; Renique, José Luís: La batalla por Puno. Conflicto agrario y nación en los Andes peruanos, IEP-SUR-CEPES, Lima, 2004. 
las autoridades consulares españolas, al mismo tiempo que, ante el temor a que sus posesiones fueran invadidas o que se produjera una sublevación, exhibió en todas sus haciendas carteles en que hizo constar su condición de español para evitar cualquier desmán que pudiera afectarle..$^{59}$

Guerra del Pacífico (1879-1884).--Varios españoles se vieron inmersos en el fuego cruzado de la violencia chilena y la exigencia de empréstitos por parte de las autoridades chilenas o peruanas para sostener la guerra. ${ }^{60} \mathrm{~A}$ continuación se relatan los casos que han podido ser documentados y que afectaron genéricamente a varios españoles, entre ellos a Ángel Ruiz en Trujillo, a Ramón Tovía Monasterio y a los mineros españoles en Cerro de Pasco, a varios comerciantes de Pisco, al conde de Guaqui en Arequipa, a Constantino Martínez del Pino en Tacna y a la viuda e hijos de Olivares en Puno.

En Trujillo, los intensos combates entre partidarios y contrarios del general Iglesias, que había firmado el Tratado de Ancón con Chile, culminaron en un saqueo indiscriminado, sin que lograran quedar al margen el conjunto de los negocios que para defenderse, e identificarse como de propiedad de ciudadanos extranjeros y neutrales, enarbolaron la bandera española, lo que dio pie a una serie de reclamaciones, sobre todo la relativa a la ocupación por las tropas del coronel Puga del edificio del Viceconsulado, edificio de propiedad de un señor Yturregui. ${ }^{61}$ A lo antedicho se sumaría el caso de Ángel Ruiz, funcionario en excedencia del Cuerpo Facultativo de Telégrafos de España, a quien el devenir de la guerra dejó sin sus emolumentos fijados en el contrato que le ligaba al gobierno peruano por cuatro años para encargarse del telégrafo, y sin que pudiera reincorporarse a su puesto en España. Sus sucesivas reclamaciones en 1881 ante el gobierno formado en La Magdalena; ante el ministro Dulanto, al paso de Iglesias por Trujillo, o tras la paz, en 1893 y 1896, no surtieron efecto, prolongándose su situación a la espera de que el Congreso contemplara una partida específica o se firmara un empréstito para atender tales reclamaciones. ${ }^{62}$

59 Comunicación personal de José Rey de Castro. 1996.

60 Guerra, Margarita: La ocupación de Lima, 1881-1883, aspectos económicos, PUCP, Lima,

61 AGA, 71/11907, el vicecónsul Juan M. González al ministro residente de España, Trujillo, 3 de agosto y 13 de octubre de 1884.

62 Ibidem, 71/11913, Ángel Ruiz al vicecónsul en Trujillo, Trujillo 1 de julio de 1896. 
En Cerro de Pasco fue asesinado Ramón Tovía Monasterio en la hacienda Angascancha por tres soldados chilenos la noche del 25 de mayo de 1882. Su herencia ascendía a 50.830 soles en billetes fiscales, que el Juzgado de 1. ${ }^{a}$ Instancia depositó en la persona de Pedro Mies. En 1886 el prefecto Guillermo Ferreyro ordenó que dicha cantidad se le entregara para los gastos de guerra, siendo ingresada en la caja fiscal. Por resolución suprema del presidente de la República se reconoció en 25 de mayo de 1893 que tal cantidad se había depositado en calidad de crédito, por lo que se reconocía el derecho de devolución de 2.633,67 soles de plata a sus herederos. ${ }^{63}$ En 1903 se logró desencallar la reclamación, pendiente de resolución ante el Congreso, tras la intercesión del vicecónsul en Cerro de Pasco y de la Legación española, alegando que "por su naturaleza del crédito no hay lugar a su consolidación y pago en bonos de la deuda interna", ${ }^{64}$ llegándose a firmar en 1903 un Protocolo de Reconocimiento de deuda. ${ }^{65}$

Los mineros españoles de Cerro de Pasco fueron conminados por el prefecto Guillermo Ferreyros a entregar un cupo mensual destinado a sostener a las tropas comandadas por el general Andrés Avelino Cáceres. En la práctica se justificaba el impuesto extraordinario como contrapartida de la exención del servicio militar obligatorio de los operarios a su servicio. Sin reconocerles sus derechos, se estaba recaudando por la vía de apremio, con la amenaza de que se les incrementaría en un $2 \%$ si no lo abonaban en el plazo de un mes. En su alegato, los mineros recordaban que las leyes internacionales les avalaban, ya que como ciudadanos de un país neutral debían estar exonerados de impuestos extraordinarios, como había reconocido el propio gobierno chileno, al eximirles durante la ocupación del Departamento en 1881 y 1882 de los impuestos extraordinarios sobre el comercio, la industria, las haciendas y los operarios peruanos adscritos y matriculados, gravámenes que sólo impusieron a los peruanos. La reclamación iba firmada por L. Gallo, Francisco Martinench, Tomás Aldecoa, José F. Gallo, Pedro y Gerónimo Gallo, Manuel Clotets, propietarios o administradores de las haciendas minerales San Miguel de Paria; Yuraganca, Huanca y San José de Bellón; Santa Teresa, Santa Rosa, Quivillata y

63 Ibidem, 71/11915, el ministro de España a E. Larrabure y Unánue, presidente del Consejo de Ministros y ministro de Relaciones Exteriores, Lima, 12 de junio de 1903.

64 ACMRREEP, Legación de España, 1901, 7 de julio de 1902.

65 El protocolo fue firmado el 27 de junio de 1903 por el ministro de Relaciones Exteriores del Perú y el enviado extraordinario y ministro plenipotenciario de España, Ramiro G. de Uríbarri, en: Novak: Las relaciones entre el Perú y España, pág. 81. 
Pampaverde; San Francisco, Yanamachay y Belén; San Antonio de Tulluranca, Tulluranca y Carmen. ${ }^{66}$

El senador español de origen arequipeño, conde de Guaqui, reclamó a través de su apoderado, José Antonio Vivanco, que se le indemnizara por los bienes que se vieron afectados cuando las tropas chilenas del batallón Curicó, al mando del comandante Carvallo Orrego, se instalaron en 1883 a modo de cuartel en una de sus propiedades, el palacio de Huasacache, a pesar de la placa que rezaba en la puerta principal "Casa del ciudadano español Conde de Guaqui". ${ }^{67}$

Constantino Martínez del Pino, residente en Tacna, suscribió con el general en jefe del ejército a principios de 1880 un contrato para proveerle de calzado por un importe de 3.800 soles. Aún en 1891 y 1899 reclamaba por la vía consular que se le abonara la deuda, tras haber perdido la esperanza de lograrlo por sí mismo. ${ }^{68}$

En Puno, Ricardo J. Bustamante, apoderado de la viuda de Olivares y de sus hijos menores, residentes en Madrid y propietarios de la hacienda Yanarico, denunciaba las altas contribuciones impuestas bajo el gobierno del general chileno J. Montero, a lo que se sumaba el cupo en ganado, que en una primera etapa sólo afectó a los peruanos, pero que el jefe supremo chileno estaba extendiendo a todos los propietarios, incluidos los extranjeros, por lo que pedían ayuda consular y, dados los buenos resultados que había tenido la intercesión del vicecónsul inglés en Arequipa, se pedía la creación de un Viceconsulado español en Puno, cargo para el que se ofrecía el demandante, quien ya asumía la representación de Argentina ${ }^{69}$

El subprefecto de Pisco exigiría contribuciones forzosas a los empresarios de la zona, para costear la expedición militar del general Iglesias sobre Ica. En concreto varios españoles reclamaron la devolución del empréstito de 1.000 soles avalado con letras sobre la Caja Fiscal de Lima. Tal monto fue resultado de una tensa negociación, en la que inicialmente se les había impuesto 4.000 soles a Fananga y Cano, 1.000 soles respectivamente a las

66 AGA, 71/11907, Viceconsulado de España en Cerro de Pasco al encargado de Negocios de España en Lima, Cerro de Pasco, 11 de marzo de 1884, adjuntando representación de los mineros españoles en Cerro de Pasco al general jefe superior político y militar de los Departamentos del Centro de esta República, Cerro de Pasco, 22 de febrero de 1883.

67 Ibidem. Eguren a Valles, 21 de diciembre de 1883.

68 ACMRREEP, Legación de España, 3 de febrero de 1899, adjuntando la instancia de Constantino Martínez del Pino, Tacna, 17 de marzo de 1898.

69 AGA, 71/11907, Ricardo J. Bustamante a Enrique Valles, encargado de negocios de España en el Perú, (Puno) Yanarico, 27 de abril de 1884. 
Casas Ramón Pasaron y Juan C. Cortina, y, ante sus reticencias, se les detuvo y amenazó con situarles en la vanguardia de las tropas, que se dirigían a Ica. ${ }^{70}$

Fuera consecuencia de los avatares de la guerra o de otros conflictos que desconocemos, lo cierto es que en 1884 los indígenas habían actuado contra la hacienda de Uchusquillo, sita en Huari, departamento de Ancash, y propiedad del súbdito español Marcelo Ruiz de Mazuela, por lo que en 1891 y 1893 se reclamaba la devolución de los bienes sustraídos. ${ }^{71}$

La Guerra Civil de 1894-1895.-Como en la Guerra del Pacífico, varios españoles se vieron afectados por el conflicto abanderado por Nicolás de Piérola y que concluyó con la destitución del presidente Andrés Avelino Cáceres, el fin del Segundo Militarismo y el inicio de la que se conocería como República Aristocrática. El país fue sacudido por un sinnúmero de montoneras al mando de caudillos locales, las cuales para sostenerse y hacer frente a los costes bélicos optaron por exigir cupos y empréstitos a comerciantes, hacendados, mineros o empresarios. La creciente presencia de extranjeros en los más diversos sectores productivos, hizo que, en buena medida, la situación les afectara, convirtiéndose para éstos en un pesado lastre económico. Tras el conflicto se abrió un amplio proceso de reclamaciones a través de sus respectivos representantes diplomáticos, para cuya resolución el gobierno peruano creo una Comisión de Reclamaciones, de la que se desconoce el conjunto de sus actuaciones y resoluciones, con la salvedad de lo relativo a la colonia italiana. Ésta promovió 77 expedientes que, en conjunto, exigían reparaciones por un monto de $517.729,10$ soles para resarcirse de los daños y perjuicios ocasionados al exigírseles cupos o por haber visto afectadas sus propiedades, destruidas sus haciendas, comercios o los más diversos establecimientos. Para su resolución, se aceptaría el arbitraje de Ramiro Gil de Urribari, ministro de España, cuyo fallo arbitral de 20 de septiembre de 1901 fijó las indemnizaciones en una suma global de $83.080,01$ soles. $^{72}$

70 Ibidem. Reclamación de José Cano y Gutiérrez, Juan C. Cortina y Ramón Pasaron al ministro plenipotenciario y enviado extraordinario de España en Lima de habérseles exigido cupo. Pisco, 8 de julio de 1884 .

71 Ibidem. Reclamación ante el Ministerio de Hacienda del Perú, 1 de abril de 1880; ACMRREEP, Legación de España, 1891, Emilio de Ojeda, 4 de octubre de 1891; 71/11912, memorando del enviado extraordinario y ministro plenipotenciario de S.M. el rey de España, Lima, 26 de julio de 1893, en que se menciona que se "aceptaría un principio de fallo arbitral que quizás allanaría las dificultades que hasta hoy se han opuesto a un equitativo arreglo".

72 Basadre, Jorge: Historia de la República del Perú, 1822-1933, Editorial Universitaria, Lima, 1963, 6. ${ }^{a}$ ed., t. X, págs. 122-123. 
Para el caso de la colonia española, intentaremos aportar una aproximación a los afectados y a sus peticiones en concepto de resarcimiento por daños y perjuicios sufridos. En un conflicto que fue fundamentalmente rural, no fue extraño que hubiera españoles a quienes se les exigieron cupos, empréstitos o directamente los productos de sus haciendas o comercios en las más diversas regiones del país —Lambayeque, Ancash, Huánuco, Carabayllo-Canta, Ayacucho, Cusco y Puno-. En concreto nos referiremos a los casos que afectaron a Salvador Olivares y Echevarría, a Federico Herrera, Nadal Más, Bartolomé Torres, Jaime Oliver, Juan Parella, Ramón Núñez, Ramón Ferrer, Juan Inchaustegui, Isidro Lambarri y la casa Forga, y a la compañía de zarzuela española de Carlos Peyres.

En Lambayeque, al comerciante Salvador de Olivares y Echevarría, natural de Orozco Ibarra (Vizcaya), las fuerzas de la coalición al mando del coronel Seminario le impusieron un cupo, a pesar de que alegara su condición de ciudadano español. Posteriormente pediría que se le compensase su aportación forzosa de 520 soles de plata, más 10 soles por un saco de arroz y otros 10 más para gratificar a los soldados. ${ }^{73}$

En Huaraz (Ancash), el prefecto Federico Herrera se valió de una serie de medidas intimidatorias para obtener recursos económicos para la causa del general Cáceres, que en el caso del comerciante Jaime Oliver fueron medidas de presión graduales como que se apostaran centinelas ante su establecimiento o su clausura, para que entregara en total 540 soles de plata $;^{74}$ o ante las reticencias de los comerciantes y socios Nadal Más y Bartolomé Torres, en septiembre de 1894, de aportar un empréstito de 500 soles, además de la imposición de guardias en la puerta del negocio, la detención de Nadal Más, sometido a un conato de fusilamiento, mientras se le conminaba para que denunciara el paradero de su socio. ${ }^{75}$

En Huánuco las fuerzas coalicionistas de los batallones Huallaga y Libres del Cerro exigirían recursos al menos a dos españoles. Juan Parella, natural de Navata (Girona), reclamó en concepto de daños y perjuicios 22.707,74 soles por el allanamiento y saqueo, el 23 de agosto de 1894, del establecimiento comercial que regentaba bajo la razón social Belisario Rosas, por las citadas fuerzas del batallón Huallaga al mando del coronel

73 ACMRREEP, Legación de España, 12 de junio y 17 de octubre de 1895.

74 Ibidem, 7 de enero de 1895, remitiendo nota del súbdito español don Jaime Olive, Ancash, 28 de octubre de 1895 .

75 Ibidem, 12 de junio de 1895, adjunta carta de Nadal Más a la Legación Española, Huaraz, 6 de mayo de 1895 . 
Augusto Durand. ${ }^{76}$ Y el gallego Ramón Núñez, propietario de la hacienda La Esperanza dedicada al cultivo de tabaco y elaboración de cajetillas de cigarrillos La República, caña de azúcar y café, hizo lo propio por un total de $30.644,90$ soles por los cupos exigidos y el conjunto de las pérdidas ocasionadas en su propiedad cuando fue ocupada el 8 de marzo de 1895 por dichas tropas, cuyo máximo responsable era el prefecto de Junín, pero que entonces actuaban a las órdenes directas del comandante general de Huánuco, Manuel David Flores. ${ }^{77}$

Ramón Ferrer, arrendatario del fundo denominado Trapiche, en la quebrada de Yanga, próxima a la de Carabayllo y Canta, reclamó el importe de 35.722 soles, por el valor de las confiscaciones a que les sometieron las fuerzas militares caceristas (26.850 soles entre 12 de octubre de 1894 y 16 de marzo de 1895) y de la Coalición dirigidas por Isaías de Piérola (8.722 soles entre 27 de octubre de 1894 y 9 de marzo de 1895) en efectos, alimentos y pastos destinados a la manutención de la tropa, caballos, ganado vacuno y menaje de su casa (150 soles). ${ }^{78}$

Juan Inchaustegui y Avaluces, natural de San Vicente de Abando, afincado en Ayacucho desde 1879, reclamó 3.882,55 soles por las pérdidas en el fundo del que era arrendatario, Ccayarpachi, por el ganado y dinero sustraído, la destrucción de alfalfares y sustracción del vino almacenado, en el transcurso de varias acciones contra la propiedad ocurridas entre el 23 de diciembre de 1894 y el 7 de enero de 1895, cuyos responsables fueron varias partidas armadas, tanto del Partido Constitucional como del Civil, en busca de avituallamientos, llegando a detenerle los civilistas acusado de espionaje. ${ }^{79}$

En el Cusco, el Viceconsulado fue allanado y registrado por orden del prefecto en 1894 en busca de dos presos políticos que se presuponía se ha-

76 AGA, 71/11912, Reclamación de Juan Parella por daños y perjuicios en la guerra civil, Huánuco, 25 de julio de 1895.

77 En su defensa Ramón Núñez recordaba, como para salvar a Huánuco de las exigencias chilenas y de los previsibles saqueos, se ofreció a surtirles de alimentos y otros bienes. ACMRREEP, 6 13, Luis del Castillo, Legación de España en el Perú, a Melitón F. Porras, ministro de Relaciones Exteriores, Lima, 25 de septiembre de 1895; Ramón Núñez al ministro plenipotenciario de S.M. la reina regente de España, Huánuco, 18 de julio de 1895. Inventario de la hacienda La Esperanza, 8 de mayo de 1895. AGA, 71/11912, Reclamación Ramón Núñez.

78 ACMRREEP, Legación de España, 14 de mayo de 1895. AGA, 71/11912, Reclamación de Ramón Ferrer.

79 Ibidem, 6 - 13, Luis del Castillo, Legación de España en el Perú, a Manuel Candamo, presidente de la Junta de Gobierno y ministro de Relaciones Exteriores, Lima, 27 julio de 1895. Adjunta solicitud y documentos probatorios de Juan Inchaustegui y Avaluzes, Ayacucho, 31 de marzo de 1895. AGA, 71/11912, Reclamación Inchaustegui. 
bían refugiado en su interior, aprovechando la ausencia en Arequipa de su titular Isidro Lambarri. Según éste el desencadenante había sido la negociación fallida de un préstamo de 2.000 soles solicitado por el prefecto a la firma M. Forga e Hijos, de la cual él era agente, al no obtener el aval de administrador de la Aduana para ser amortizado en despachos de aduana a Mollendo. ${ }^{80}$ A su regreso al Cusco el vicecónsul fue detenido por el prefecto, general Más, tasándose su libertad en un cupo de dos mil soles de plata. ${ }^{81} \mathrm{~A}$ los pocos días Lambarri acudió en ayuda del español y comerciante Leonardo López, asentado en Urubamba, una zona ocupada desde el 6 de marzo por el Partido Coalicionista, y ante el temor de ser saqueado, optó por viajar al valle Sagrado junto con los representantes de las firmas Eumel Hermanos y Braillard Hermanos y $C^{a}$. En Urubamba, tras negociar con el jefe de los coaligados y obtener garantías, sacaron a López de su escondite y le pusieron de nuevo al frente del negocio. Ya de regreso, el general Más les retiró el salvoconducto y les impuso multas que ascendían respectivamente a 2000 y 4.000 soles, que una vez negociadas fueron rebajadas a la mitad y consideradas un empréstito. Sólo después del óbito del general Más, reclamaron el reintegro de dichas cantidades al gobierno, a través de la Legación Española. ${ }^{82}$

Carlos, Francisco y Oscar Peyres eran familiares y empresarios de la compañía de zarzuela española Carlos Peyres, con 34 integrantes, quienes tras más de quince años de actuar por Sudamérica, recalaron en Puno, a la espera de su equipaje procedente de La Paz. Con la mala suerte de que mientras organizaban varias funciones, con las que costear entretanto los gastos de su manutención, la ciudad fue tomada la noche del 9 de octubre de 1894 por las tropas pierolistas al mando del sargento mayor Enrique Galdos. Tras ser reconquistada por los caceristas, fueron detenidos, sufrieron un conato de fusilamiento en la plaza, para ser luego conducidos a Arequipa, donde permanecerían detenidos más de dos meses, hasta que los buenos oficios del cónsul M. Forga les permitieron recobrar la libertad. Por todos los daños sufridos exigieron 15.000 soles de indemnización, cantidad necesaria, a su entender, para reorganizar la compañía y saldar las pérdidas de guardarropía, música y los gastos de alojamiento de nueve personas durante los 70 días que duró su detención en Arequipa. ${ }^{83}$

80 ACMRREEP, Legación de España, 25 de agosto de 1894. Refería además la detención de tres viajeros, dos franceses y un español, sin causa alguna, quienes se volvieron a Lima.

81 Ibidem. Legación de España, 16 de abril de 1895.

82 Vicecónsul en Cusco al cónsul de España, Cusco, 22 de abril de 1895.

83 AGA, 71/11912, Reclamación Peyres, 23 de junio de 1895, en la que consta su traslado a la Comisión especial de Reclamaciones. 
Desconocemos la resolución final de la mayoría de las reclamaciones mencionadas por parte de la Comisión de Reclamaciones. Entre las que disponemos del fallo, estuvo la de Salvador de Olivares y Echevarría, encontrándose justas sus peticiones, no así los 10 soles de gratificaciones, ${ }^{84}$ mientras que a Juan Inchaustegui se le cuestionó que incluyera el valor de animales que estaban invernando en su explotación al no ser de su propiedad. ${ }^{85}$ Es muy poco, sobre el total de reclamaciones, pero el resultado debió ser más abultado a favor de la colonia española, si interpretamos cabalmente el Tratado Adicional al de Paz y Amistad firmado el 18 de junio de 1898 entre el Perú y España, en cuyo artículo IV se fijaba que "los dos Gobiernos no podrán recíprocamente exigirse responsabilidad por los daños, vejámenes o exacciones que los nacionales de uno de los dos Estados sufrieren en el territorio del otro por parte de los sublevados, en tiempo de insurrección o guerra civil o en sediciones y motines", no considerándose responsables "sino de sus propios actos o de los que hayan ejecutado sus agentes en ejercicio de sus funciones", y el artículo VI establecía que "los españoles en el Perú y los peruanos en España no tendrán derecho a la intervención diplomática, sino en el caso de manifiesta denegación de justicia". ${ }^{86}$ En la práctica suponía cerrar, cara al futuro, el proceso que había permitido a los españoles reclamaciones tan amplias como las que habían tenido lugar a raíz de la Guerra del Pacífico y de la Civil posterior.

Ello se demostraría en adelante ya que si bien seguirían exigiendo cupos, como ocurrió en 1899, cuando la montonera Durand secuestrara a Alejo Bustelo, vicecónsul de España en Supe y Huacho, por negarse a pagar la contribución forzosa:;7 determinados cónsules como el de Arequipa, Miguel Forga, se mostrarían en adelante renuentes a intervenir, como muestra el caso de Esteban M. Cáceres, farmacéutico, afincado en Camaná cuando, en 1902, su casa fue tiroteada por un grupo de cuatro personas, cuyo cabecilla era el mismo, según Cáceres, que había secuestrado y herido al subprefecto Salazar en 1894. Los hechos se inscribían en el clima de descontento popular ante las medidas tomadas por el gobierno para evitar la circulación de pesetas de araña -moneda feble boliviana- e intro-

84 ACMRREEP, Legación de España, 12 de junio y 17 de octubre de 1895.

85 Ibidem, 6 - 13, Luis del Castillo, Legación de España en el Perú, a Manuel Candamo, presidente de la Junta de Gobierno y ministro de Relaciones Exteriores, Lima, 27 julio de 1895. Adjunta solicitud y documentos probatorios de Juan Inchaustegui y Avaluzes, Ayacucho, 31 de marzo de 1895. AGA, 71/11912, Reclamación Inchaustegui.

86 Archivo Digital de la Legislación en el Perú, www.congreso.gob.pe.

87 ACMRREEP, Legación de España, 15 de octubre de 1899. 
ducir la moneda nacional como mecanismo de canje comercial, situación de la que no era ajena la resistencia de los comerciantes para aportar donativos que favorecieran el aumento de circulante y la actitud vacilante del gobierno que, tras varias promesas, no terminaba de remitir moneda nacional circulante.$^{88}$ Forga, sin entrar en el fondo de la cuestión, era contrario a atender la demanda de Cáceres, aduciendo, entre otras cosas, que según el Tratado Adicional de Paz y Amistad de 1898, sólo era dable una vez que "agotados todos los recursos de tramitación y apelación judicial, resulte probada la denegación de justicia y el Gobierno de España enterado del asunto en todos sus pormenores, resuelva si debe o no proceder a la reclamación diplomática". ${ }^{89}$

Pero además debemos añadir un corolario. Si cierta historiografía ha señalado que habrían sido los cupos las causas de quiebra de los sectores modernizadores nacionales,$^{90}$ nos encontramos con que los ciudadanos extranjeros lograron resarcirse de sus contribuciones forzosas gracias a las arcas del Estado, lo que les situaba en condiciones ventajosas frente a los peruanos que debieron soportar el peso de los diversos conflictos, sin compensación alguna. Tampoco podamos obviar que la raíz de la política de cupos y empréstitos forzosos impuesta durante la Guerra Civil de 18941895 por las diversas autoridades regionales, tenía su razón de ser en la política de descentralización fiscal iniciada como una de tantas medidas que llevarán a la regeneración nacional tras la derrota que supuso la Guerra del Pacífico y que terminó en una grave crisis hacendística y en la quiebra de las arcas departamentales. ${ }^{91}$

La revolución del capitán G. Cervantes, Loreto, 1921.-La revolución del capitán Guillermo Cervantes ha sido interpretada por F. Barclay y F. Santos como el primer movimiento de tipo regionalista en Loreto, crítico tanto contra el gobierno limeño, como contra la elite comercial, en una

88 Cáceres había pedido garantías al cónsul para su persona desde al menos 1894. AHCMRREEP, Prefecturas, 2 - O - E, 1902. D J. Parra, prefecto de Arequipa, al oficial mayor, Arequipa, 20 de octubre de 1902; Hernán Velarde, oficial mayor, al prefecto de Arequipa, Lima, 30 de septiembre de 1902.

89 AGA, 71/11916, Miguel Forga al ministro plenipotenciario de España en Lima, Arequipa, 27 de abril de 1903.

90 Contreras, Carlos: "Apogeo y crisis de la Teoría de la Dependencia en la historia económica sobre la República”, Histórica, XXVI, 1-2, Lima, 2002, pág. 517.

91 Contreras, Carlos: "El poder de gobernar y el poder de cobrar. Autoridades políticas locales en el Perú a finales del siglo XIX”, en Aljovín, Cristóbal y Jacobsen, N. (eds.): Cultura política en los Andes (1750-1950), UNSM-IFEA, Lima, 2007, págs. 155-179. 
coyuntura de crisis del modelo extractivo cauchero que había dominado durante décadas. Sus argumentos iban desde criticar la alianza del prefecto leguista con las firmas comerciales importantes, que pasaron a beneficiarse de grandes contratos, exenciones fiscales e impunidad comercial; la carencia de moneda circulante, situación en la que los comerciantes más destacados imponían las mercancías al crédito y la falta de recursos aportados por el Estado, al punto que los funcionarios llevaban más de un año sin percibir sus salarios. Cervantes contó con un amplio apoyo popular, expresión de un sentimiento que se había organizado en torno a la Liga Loretana, fundada en 1913. Sus presupuestos eran regionalistas, oponiéndose al control que ejercía el grupo al que se denominaba despectivamente La Cueva, visto como oligárquico y conformado por quienes detentaban los intereses de las grandes empresas comerciales, que en parte eran extranjeros. ${ }^{92}$

Éste fue de lejos el devenir político en el que se inmiscuyeron, voluntaria o involuntariamente, más españoles. Algunos fueron acusados de haber intervenido directamente en los acontecimientos, mientras que otros sufrieron en sus bienes la radicalidad de la protesta. La Legación española intervino, a instancias del cónsul en Loreto, para:

a) conocer el paradero, el 7 de marzo de 1922, de varios detenidos en Iquitos y llevados presos en la cañonera América, que había zarpado el 20 de enero de 1922 de dicho puerto: Victoriano Gil, Manuel Rodríguez Lira, Juan Ramos, Manuel Vázquez Suárez, José Peris, Jaime Pons, Manuel Martín y José Prado; ${ }^{93}$

b) evitar la expulsión de Iquitos de Cristóbal Ruiz, carpintero; José Rivas, fabricante de maderas; Liberato Valleve, cerrajero; Simón Abellón, panadero, todos ellos firmantes de un acta, cuyo tenor no se especificaba, justificando que lo habían hecho forzados y que varios italianos que también la suscribieron no habían sido inculpados; ${ }^{94}$

c) solicitar reiteradamente la libertad de Francisco del Campo López, detenido y sus bienes confiscados en Yurimaguas, remitido luego a Lima y confinado en la isla de Taquile. ${ }^{95}$

92 Santos y Barclay: La frontera domesticada, pags. 189-197.

93 ACMRREEP, 6 - 13, Nota verbal de la Legación de España en Lima, Lima, 7 de marzo de 1922.

94 Ibidem. Jaime Ojeda, legación de España en Lima, a Alberto Salomón. ministro de Relaciones Exteriores, Lima, 24 de marzo de 1922.

95 Ibidem. Notas verbales de la Legación de España en Lima, Lima, 17 de febrero y 7 de marzo de 1922, Jaime Ojeda a Alberto Salomón, ministro de Relaciones Exteriores, Lima, 4 de marzo de 1922. 
Es difícil hacer una aproximación, a la vista de los pocos datos existentes hasta el momento, de quiénes eran los españoles que se sumaron a la intentona del capitán Cervantes. Además de la información consular, se sabe que algunos implicados - Manuel Rodríguez Lira, Victoriano Gil Ruiz, Manuel Vásquez Jares - serían detenidos, embarcados en la cañonera América, y tras una avería, trasladados a la lancha Clavero y luego deportados a Brasil. Sus profesiones nos indican que se trataba de gentes dedicadas a oficios artesanales. Durante el trayecto falleció José Peris, soltero, "rico industrial", con 18 años de residencia en Iquitos. ${ }^{96}$ José Manuel Rodríguez Lira, natural de Vigo, era dueño de la casa Fotografía Lira, ubicada en la calle del Progreso 100-8, tuvo un cierto prestigio local como fotógrafo, llegando a estar al servicio de la casa Arana en relación a los sucesos del Putumayo. ${ }^{97}$ Había residido en Manaos, donde fue nombrado vicecónsul en 1900, si bien en 1902 residía ya en Iquitos, tras abandonar, por causas desconocidas, sus obligaciones y la documentación consular. ${ }^{98}$ Desde su llegada encabezó una férrea oposición al vicecónsul José Altimira, al que tildaba de ser un simple albañil, casi analfabeto ${ }^{99} \mathrm{y}$ de mantener posiciones cuevistas. ${ }^{100}$ Victoriano Gil Ruiz era también fotógrafo, socio en algún momento de Rodríguez Lira, residiendo en Iquitos desde 1911, y Manuel Vásquez Jares era sastre.

Como al mismo tiempo hubo quienes plantearon reclamaciones por daños elevados al gobierno peruano, debemos suponer que no hubo una posición monolítica dentro de la colonia española. En mayo de 1923 se presentó una relación de cinco afectados por arbitrariedades, tanto de los revolucionarios, como de las autoridades peruanas leales. Entre la relación de afectados estaban Barcia Hnos., Rodríguez López Garnelo, "varios españoles que se citan", Victoriano Gil Ruiz, José Caballero Ruiz y David González Rodrí-

96 Jornal do Comercio, Manaos, n. ${ }^{\circ}$ 6416, 7 de marzo de 1922; La Raza, Río de Janeiro, 18 de noviembre de 1922, en: Torres Videla, Samuel: La revolución de Iquitos (Loreto-Perú), Tipografía España, Pará, 1923, págs. 230-234.

97 Comunicación personal de J. P. Chaumeuil.

98 AMAE, Personal, Letra R, año 1900, núm. 1161, Signatura P 213, Expediente 11891, José Manuel Rodríguez Lyra. De de la Barre, Legación de España en Brasil, al ministro de Estado, Petropoli, 14 de septiembre de 1900; su destitución en los despachos n. ${ }^{\text {s }} 30$ y 83 de la Legación de España, Río de Janeiro, 28 de febrero y 15 de mayo de 1904. AHCMRREEP, Prefecturas, 2 - O - E, 1905 (2), Consulado de Lima-Callao al Ministerio de Relaciones Exteriores, Lima, 16 de octubre de 1905.

99 AMAE, P 260, Exp 16725, Altimira Mota, José. De Manuel Rodríguez Lira a Álvaro Figueroa y Torres Mendieta y Romo, Iquitos, 22 de enero de 1916; Manuel Rodríguez Lira al ministro de Estado, Madrid, Iquitos (Perú), 31 de diciembre de 1917, remitiendo el acta firmada por 61 españoles pidiendo la substitución de Altimira por Rodríguez Lira, en Iquitos, 20 de noviembre de 1917.

100 Ibídem, El Latero, Año VII, núm. 315. 
guez, reclamando los cuatro primeros un total de 11.774.0.20 Lp - 364.827, 1.316.493, 92.700 y 10.000 Lp respectivamente - y el último la devolución de varias mercancías. El caso más grave había sido el de Victoriano Gil Ruiz, propietario del único taller de artes gráficas de Iquitos, al que, según el, se le obligó a imprimir impresos y papel moneda. ${ }^{101}$

El 6 de junio de 1923 el gobierno peruano respondía a la representación española declinando cualquier responsabilidad y remitiendo a los afectados a la vía judicial para que lograran la reparación y castigo de los autores de los atropellos de los que habían sido víctimas. ${ }^{102}$ A pesar de lo cual tenemos constancia de que la Legación española y el vicecónsul en Iquitos usaron sus buenos oficios en varios casos. Así sucedió al menos respecto a Rodrigo López Garnelo, quién había visto como su lancha Vierzo era llevada por los rebeldes el 31 de diciembre de 1921 en su huida por el río Napo, siendo confiscada, junto a otras, por el gobierno ecuatoriano. ${ }^{103}$ En 1923 se pedía permiso para trasladarla desde donde estaba, Puerto Armenia de Nicolás Torres, o venderla in situ. ${ }^{104}$ Aún en 1925 el cónsul español en Iquitos, José Altimira, volvía a insistir a la Cancillería peruana para que se gestionara ante el gobierno ecuatoriano la devolución de la citada lancha. ${ }^{105}$

Como también se actuó a favor de Manuel Vásquez Jares, quién reclamaba 816.5.30 Lp, por las mercancías extraídas forzosamente de su comercio y pagadas con billetes emitidos por los revolucionarios, ${ }^{106} \mathrm{y}$ de David González y José Caballero ${ }^{107}$ a raíz de que fuera desestimada por la Corte Superior de Justicia, en sentencia de 7 de enero de 1925, su demanda de

101 ACMRREEP, 6 - 13, Alberto Salomón a Jaime Ojeda, enviado extraordinario y ministro plenipotenciario de España, Lima, 6 de junio de 1923.

102 Ibidem, N. ${ }^{\text { }} 31$, Alberto Salomón a Jaime Ojeda, enviado extraordinario y ministro plenipotenciario de España, Lima, 6 de mayo de 1923.

103 Ibidem. Jaime Ojeda, legación de España en Lima, a Alberto Salomón. ministro de Relaciones Exteriores, Lima, 14 de enero de 1924.

104 Ibidem. El mismo al mismo, Lima, 26 de mayo de 1923.

105 Ibidem, 2 - O - E, 1925, Prefectura Loreto al oficial mayor, Iquitos, 27 de febrero de 1925.

106 Ibidem, 6 - 13, Jaime Ojeda, legación de España en Lima, a Alberto Salomón. ministro de Relaciones Exteriores, Lima, 8 de enero de 1925, adjuntando carta de Manuel Vásquez Jares, Lima, 3 de enero de 1925. Manuel Vásquez Jares y otros españoles habían pedido garantías en 1919, alegando haber sido maltratados por asuntos políticos en Iquitos, aunque el descargo del subprefecto reducía los hechos a un incidente por asuntos personales entre los señores Vásquez Jares y Antonio Romano con José María Torres y Estanislao Nauparin, en el que resultaron heridos Vásquez Jares y Torres, en ibidem, 2 - O - E, 1919, Subprefectura e intendencia de policía del Bajo Amazonas al prefecto, Iquitos, 21 de noviembre de 1919.

107 Ibidem, 6 - 13, Jaime Ojeda, Legación de España en Lima, a José Rada y Gamio, presidente del Consejo de Ministros y ministro de Relaciones Exteriores, Barranco, 20 de abril de 1927, adjuntando copia de la solicitud elevada por José Caballero Ruiz y David González Rodríguez, Iquitos, 1 de enero de 1927. 
4.500 soles contra la casa comercial Kahn y Cía. de Iquitos por el decomiso de 9.000 kilos de pescado (paiche) -4.000 propiedad de José Caballero y 5.000 de David González- y cuatro pacotes de vaca marina —o 50 piezas, propiedad de José Caballero-, efectuado el 18 de febrero de 1922 en el fundo San Antonio en el río Tigre, regentado por J. Caballero. En el acto intervinieron el comandante de la lancha Elisa, Guillermo Pinedo, el factor de dicha compañía, Santiago Flores, el teniente de ejército F. Fonseca y el comisario del Huallaga, César Alarco. ${ }^{108}$

Todavía en 1933 seguían pendientes las reclamaciones de Rodríguez Lira $^{109}$ y Gil Ruiz, cuando las autoridades locales, en respuesta a una consulta del encargado de negocios de España, afirmaban que no se había encontrado la reclamación en el archivo de la Prefectura. ${ }^{110}$

Una valoración del comportamiento de la colonia española, a partir de los datos que hemos recopilado, nos lleva a proponer como hipótesis interpretativa lo siguiente: el hecho de que el vicecónsul en Iquitos, el catalán José Altimira Motta, fuera tildado de cuevista, se correspondía en parte con su posición económica y social, pues era constructor, comerciante, regidor de la municipalidad de Iquitos, delegado de la Casa América, siendo además cónsul encargado de los asuntos consulares de Grecia, ${ }^{111}$ o que entre los que vieron afectados sus bienes estuviera la firma comercial Barcia Hnos., una de las más importantes en aquella plaza, mientras que los detenidos o deportados pertenecían sobre todo a sectores artesanales, nos permite apuntar que la colonia española en Loreto mostró en 1921 la división con que afrontaba

108 Ibidem, 2 - O - E, 1927, Prefectura de Loreto al oficial mayor, Iquitos, 10 de mayo de 1927. Basadre cita el enfrentamiento entre la cañonera América y la lancha Elisa contra la expedición enviada desde Lima, al mando del capitán Genaro Matos. Si bien este venció y entró en Iquitos el 13 de enero, un mes antes de los sucesos denunciados, podemos pensar que de alguna forma tuvieron relación. Basadre: Historia de la República del Perú..., t. XIII, págs. 92-94.

109 Rodríguez Lira residía en 1935 en Manaos, como se infiere de la denuncia contra el español Carlos Morey Canalejas, señalado como espía a favor de Colombia, de estafar a su habilitador en la extracción de madera, el catalán Magín Boria. En el expediente, las autoridades peruanas se referían a Rodríguez Lira, recordando su condición de deportado, que "no es persona lo suficientemente honorable", como se deducía de los informes de sus paisanos que lo tenían por "persona muy amante de la intriga y el tinterillaje". ACMRREEP, 2 - O - E, 1935, Oscar Mavila, prefecto de Loreto, al oficial mayor, Iquitos, 7 de mayo de 1935, adjunta el expediente letra D, n. 206 relacionado al informe emitido por la Sección de Investigaciones sobre la persona del individuo Carlos Morey Canalejas, de nacionalidad española; prefecto de Loreto al jefe de la Guardia Civil y Policía del Destacamento Autónomo del Oriente, le remite el oficio del oficial mayor 23.3.ultm., que incluye un despacho de 6 del mes en curso del cónsul en Manaos. Informe de la sección de Investigaciones, oficial 2. ${ }^{\circ}$ de investigaciones, Rossell Cruz, Iquitos, 22 de mayo de 1935.

110 Ibidem, 1933, Prefectura de Loreto al oficial mayor, Iquitos, 7 de abril de 1933.

111 Martínez Riaza: “A pesar del gobierno...”, págs. 273-279. 
los tiempos de la crisis del caucho, implicándose en el devenir político regional. Si los que se sumaron de una u otra forma a la revolución de Cervantes pareciera que habían sido los grandes perdedores, al ser detenidos o deportados, el futuro se encargaría de mostrar que el boom del caucho había tocado a su fin. A la postre, los que parecía que volvían a imponer el orden, el gobierno central y las grandes casas comerciales, no pudieron evitar el fin definitivo del modelo económico cauchero. Para el caso que nos ocupa, la firma Barcia Hnos. no lograría evitar la ruina, mientras que muchos de los españoles residentes en Loreto o bien emigraron paulatinamente hacia la costa, o bien redefinieron sus explotaciones hacia la economía fundaria. Y, como colofón, señalar el caso de Gil Ruiz que aparece como directamente implicado, deportado y, al mismo tiempo, reclamando daños y perjuicios por los destrozos que padeció su taller de artes gráficas encargado de la emisión de papel moneda de los revolucionarios, un caso más de verdades a medias, en el que es difícil dilucidar las intenciones del personaje.

\section{Conclusiones}

El recorrido por los asuntos que afectaron a los españoles afincados en los más diversos rincones del Perú nos ha permitido tener una cierta panorámica sobre su realidad y preocupaciones. Desconocemos a fecha de hoy cuantos españoles se afincaron en el país andino entre 1870 y 1945, al no existir un registro central de extranjería, o en el caso de la selva ni siquiera un registro de entradas, y al no haber sido posible consultar la documentación consular, con la salvedad de Iquitos. Es cierto que no todo el mundo tuvo tanto que perder que justificara el recurso a las autoridades diplomáticas para defender sus intereses, lo que por si sólo nos deja, a excepción de las defunciones, con una información referida únicamente a los estratos más exitosos. De todas formas nos atreveremos a plantear algunas hipótesis, que puedan ayudar en futuros estudios. La colonia asentada en el norte, costa y en valles cálidos de la sierra dirigió sus miras hacia la agricultura de exportación — algodón y azúcar — o vinculada a la producción tropical — tabaco, aguardiente de caña-. En la sierra central hubo un no desdeñable grupo que orientó sus actividades a la minería en Cerro de Pasco o Huarochirí. En el sur - Arequipa, Mollendo, Cusco, Puno-, un núcleo emprendedor, se situó en segmentos de la economía más modernizadora, vinculados al circuito lanero y al comercio interior al por mayor o 
de exportación. Lo que no impidió la presencia española en la agricultura y ganadería que podríamos llamar tradicional, situada en las más diversas zonas de sierra, desde Ancash a Puno. Sin embargo, donde la presencia española se mostró más numerosa y diversificada fue en la Amazonia, constituida por múltiples sectores profesionales, desde artesanos y pequeños productores agrícolas a grandes caucheros y comerciantes.

En conjunto, los españoles buscaron el amparo consular cuando vieron lesionados sus intereses legales. Bien fuera para defenderse de la compleja política peruana o bien por considerar que sus intereses de toda índole eran afectados por los más diversos motivos. Podría concluirse que, además de las garantías que la vía administrativa y la jurisdicción civil y penal peruanas les aseguraba, los españoles mantuvieron una vía de reivindicación abierta a través de la búsqueda de amparo ante sus representantes consulares. En tal sentido, el mantener la nacionalidad española, a pesar del arraigo de muchos de ellos, era una suerte de paraguas legal, que les protegía de una cierta inseguridad jurídica que parece haberse instalado en sus ánimos, aunque ello no fuera verbalizado.

Un punto de quiebra en la intervención de los agentes consulares a favor de los intereses de los migrantes españoles, se produjo a raíz de la amplitud de las reclamaciones incoadas después de la Guerra Civil (18941895), cuando ambos Estados redefinieron sus relaciones con el nuevo Tratado de 1898, lo que obligó a recurrir a la vía judicial para resolver los casos conflictivos. Aunque como constatamos, ello no impidió que en ocasiones especialmente complejas, desde la representación hispana se insistiera en la defensa de los intereses de sus conciudadanos. Una realidad que siempre les dejó en mejor situación para rehacer su prestigio y hacienda, que la que tuvieron los propios peruanos. Lo que nos lleva a concluir que, en última instancia, si cierta migración extranjera fue tan exitosa en el Perú, quizás fuera debido a su capacidad de servirse en todo momento de su condición de neutrales, y de recurrir a múltiples artilugios, como izar sus banderas nacionales y colgar carteles identificativos, para sortear la violencia política o buscar el amparo de sus respectivos cónsules intentando resarcirse de las posibles pérdidas económicas fuera consecuencia de cierta indefensión jurídica, real o supuesta, o de los cupos o empréstitos impuestos en las guerras que asolaron el país en las últimas décadas del siglo XIX. 